\title{
Modular Design and Implementation of an Automatic Power Factor Regulator for Energy Savings on Fishing Vessels
}

\author{
Chien-Hsing Lee \\ Department of Systems and Naval Mechatronic Engineering, National Cheng Kung University, Tainan, Taiwan \\ Shih-Hsien Hsu \\ Department of Electrical Engineering, Feng Chia University, Taichung, Taiwan, R.O.C., shihhhsu@fcu.edu.tw \\ Joe-Air Jiang \\ Department of BioMechatronics Engineering, National Taiwan University, Taipei City, Taiwan
}

Follow this and additional works at: https://jmstt.ntou.edu.tw/journal

Part of the Fresh Water Studies Commons, Marine Biology Commons, Ocean Engineering Commons, Oceanography Commons, and the Other Oceanography and Atmospheric Sciences and Meteorology Commons

\section{Recommended Citation}

Lee, Chien-Hsing; Hsu, Shih-Hsien; and Jiang, Joe-Air (2021) "Modular Design and Implementation of an Automatic Power Factor Regulator for Energy Savings on Fishing Vessels," Journal of Marine Science and Technology. Vol. 29: Iss. 3, Article 12.

DOI: $10.51400 / 2709-6998.1443$

Available at: https://jmstt.ntou.edu.tw/journal/vol29/iss3/12

This Research Article is brought to you for free and open access by Journal of Marine Science and Technology. It has been accepted for inclusion in Journal of Marine Science and Technology by an authorized editor of Journal of Marine Science and Technology. 


\title{
Modular Design and Implementation of an Automatic Power Factor Regulator for Energy Savings on Fishing Vessels
}

\author{
Chien-Hsing Lee ${ }^{a}$, Shih-Hsien Hsu ${ }^{b, *}$, Joe-Air Jiang ${ }^{c}$ \\ ${ }^{\text {a }}$ Department of Systems and Naval Mechatronic Engineering, National Cheng Kung University, Tainan, 701, Taiwan \\ ${ }^{\mathrm{b}}$ Department of Electrical Engineering, Feng Chia University, Taichung, 407, Taiwan, ROC \\ ${ }^{\mathrm{c}}$ Department of BioMechatronics Engineering, National Taiwan University, Taipei City 106, Taiwan and Department of Medical \\ Research, China Medical University Hospital, China Medical University, Taichung, 40447, Taiwan
}

\begin{abstract}
This study describes the experiences of modular design and implementation of an automatic power factor regulator for improving energy efficiency on Taiwanese longline fishing vessels. The load capacities of such vessels are typically divided into three categories, depending on the gross tonnage or fish carrying capacity: less than $100 \mathrm{~kW}$, from $100 \mathrm{~kW}$ to less than $250 \mathrm{~kW}$, and larger than $250 \mathrm{~kW}$. For attaining proper power factor improvement, a compensation unit with a total of $30 \mathrm{kVar}, 60 \mathrm{kVar}$ and $90 \mathrm{kVar}$ was sized and assembled with capacitors of 10, 15 and $20 \mathrm{kVar}$ to enable control within 12 steps. Slots for additional capacitors of $10 \mathrm{kVar}$ were reserved and connected in parallel. Based on the experiences, fuel consumption can be reduced and the payback period of the implemented equipment occurs to be within a little more than a year.
\end{abstract}

Keywords: Power factor correction, Energy savings, Diesel engine generator

\section{Introduction}

W ITH the rising fuel prices and the regulated efforts in reducing harmful emissions, it is important to ensure that marine diesel engines operate in a highly efficient manner. Typically, the engine generator set on fishing vessels is designed at a power factor of 0.8 lagging that results in lower operating efficiency. This can, however, be achieved by using new equipment and systems or by improving operating procedures [1]. On land, over-exciting generator and power factor correction are two alternatives that are often used to increase the electrical system's efficiency. Since there is not much to be gained by over-exciting the generator, the genset still supplies the same apparent power. Thus, this study chooses to correct the power factor on the vessel's electrical network by adding parallel capacitors $[7,8]$.

According to a report released by the Fisheries Agency of Taiwan in 2018, Taiwanese tuna fishing fleet numbers are about 135 boats and the vessel's electrical network often operates at a lagging power factor between 0.7 and 0.8 , resulting in poor energy performance. Although various techniques of power factor improvement have been developed to provide the compensation requirements for industrial and commercial applications on land, there are few works in literature concerning the power factor in marine electrical systems $[2,3,4,5,6,7,8,9,10]$. In the previous work [2], the authors have examined and confirmed look-up table and simple approximation

Received 22 September 2019; revised 23 September 2020; accepted 30 October 2020.

Available online 25 June 2021.

* Corresponding author.

E-mail address: shihhhsu@fcuoa.fcu.edu.tw (S.-H. Hsu). 
approaches that can be used to predict alternator fuel consumption for existing fishing vessels with the installation of capacitor banks for power factor correction. Such study brings attention to the need in modular design of an automatic power factor regulator (APFR) for power factor compensation purposes in installations with marine electrical systems. Moreover, due to a confined space on a ship, the modular design of APFR may have numerous advantages to be used in the ship electrical network such as easy and quick installation and maintenance, minimizing cost and savings in design time. Therefore, this study focuses on describing the experiences of modular design and implementation of the APFR on a main enginedriven alternator to enhance ship energy efficiency in terms of fuel savings.

\section{Modular design of a compensation unit}

Based on the survey conducted by the Fisheries Agency of Taiwan in 2018, Taiwanese tuna longline fishing vessels can be classified under three different categories by their load capacities as:

- Low: installs less than $100 \mathrm{~kW}$.

- Medium: from $100 \mathrm{~kW}$ to $250 \mathrm{~kW}$.

- High: greater than $250 \mathrm{~kW}$.

To simplify the selection of a capacitor bank in $\mathrm{kVar}$ for the three types of loads, Table 1 lists a user's choice of a compensation unit when a measured power factor of a vessel is considered to be compensated in order to attain a power factor of 0.9 0.95 lagging. Depending on the size of a compensation unit, it is assembled with capacitors of equal size or of different size. For example, a basic unit with a total reactive power of $90 \mathrm{kVar}$ consists of three capacitors of $10 \mathrm{kVar}$ each and four capacitors of $15 \mathrm{kVar}$ each. In addition, compensation banks with three withdrawable power capacitors of $10 \mathrm{kVar}$ each (i.e., $\mathrm{N}=3$ ) enable compensation in fine-stepping manner for power factor correction. Fig. 1

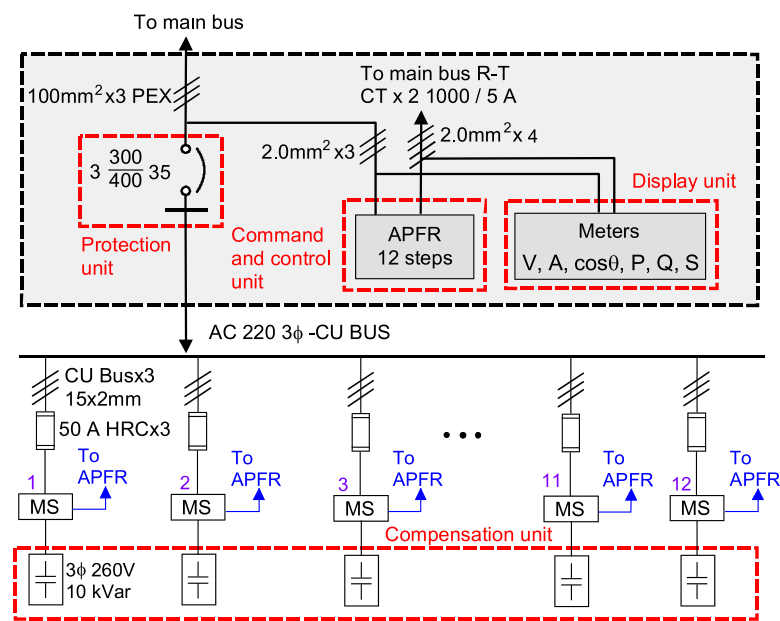

Fig. 1. Single-line diagram of the designed power factor correction unit with a total of $120 \mathrm{kVar}$ for installation on a ship electrical system.

depicts a schematic circuit diagram of a compensation unit with a total of $120 \mathrm{kVar}$, for instance, assembling with 12 capacitors of $10 \mathrm{kVar}$ each to enable control in 12 steps, corresponding to a basic unit of nine capacitors and a spare unit of three capacitors for installation in a vessel's electric network.

\section{Calculation of fuel consumption saving with adding capacitors}

This study considers three types of load capacities on Taiwanese tuna longline fishing consisting of a total load lower than $100 \mathrm{~kW}$, greater than $100 \mathrm{~kW}$ but less than $250 \mathrm{~kW}$, and higher than $250 \mathrm{~kW}$. The installation procedures of a compensation unit on a target vessel are briefly described below.

Step 1. Inspect the energy use of a ship. This step is to obtain the output capacity and efficiency of an alternator as well as to acquire the active power, reactive power, power factor (pf) and fuel consumption for a voyage.

Step 2. Compute the necessary compensation reactive power. For a ship at a load of power factor

Table 1. Size of a compensation unit for the three types of loads.

\begin{tabular}{llllll}
\hline Type of loads & Size of a unit & Type of Model & Number of steps & Basic unit & Number of spare units \\
\hline Low & $30 \mathrm{kVar}$ & $\mathrm{C}_{10 \mathrm{kVar}}^{3}+\mathrm{N}$ & 6 & $10 \mathrm{kVar} \times 3$ & $\mathrm{~N}=1$ \\
Medium & $60 \mathrm{kVar}$ & $\mathrm{C}_{10 \mathrm{kVar}}^{6}$ & 6 & $10 \mathrm{kVar} \times 6$ & $\mathrm{~N}=0$ \\
& $60-80 \mathrm{kVar}$ & $\mathrm{C}_{15 \mathrm{kVar}}^{4}+\mathrm{N}$ & 6 & $15 \mathrm{kVar} \times 4$ & $\mathrm{~N}=2$ \\
High & $90-120 \mathrm{kVar}$ & $\mathrm{C}_{10 \mathrm{kVar}}^{9}+\mathrm{N}$ & 12 & $10 \mathrm{kVar} \times 9$ & $\mathrm{~N}=3$ \\
& & $\mathrm{C}_{10 \mathrm{kVar}}^{3} \mathrm{C}_{15 \mathrm{kVar}}^{4}+\mathrm{N}$ & 12 & $10 \mathrm{kVar} \times 3$ & $\mathrm{~N}=3$ \\
& & & $15 \mathrm{kVar} \times 4$ & $\mathrm{~N}=3$ \\
& & $\mathrm{C}_{10 \mathrm{kVar}}^{3} \mathrm{C}_{20 \mathrm{kVar}}^{3}+\mathrm{N}$ & 12 & $20 \mathrm{kVar} \times 3$ & \\
\hline
\end{tabular}

Note: $\mathrm{N}$ is the number of a withdrawable capacitor module of $10 \mathrm{kVar}$. 
0.8 lagging or below, it requires to correct the power factor by adding parallel capacitors. The required capacity of capacitor banks in kVar to achieve a desired power factor can be calculated as follows:

$$
\begin{aligned}
C_{k V a r}=P_{\max }[ & \tan \left(\cos ^{-1}\left(p f_{\text {original }}\right)\right) \\
& \left.-\tan \left(\cos ^{-1}\left(p f_{\text {desired }}\right)\right)\right]
\end{aligned}
$$

where $\mathrm{C}_{\mathrm{kVar}}$ is the necessary capacitor power rating (kVar), $\mathrm{P}_{\max }$ is the maximum load power drawn from the bus $(\mathrm{kW}), \mathrm{pf}_{\text {original }}$ is the original power factor, and $\mathrm{pf}_{\text {desired }}$ is the desired power factor. This study installs a withdrawable capacitor module of $10 \mathrm{kVar}$ with an explosion-proof structure to build capacitor banks for automatic compensation of 6 to 12 electrical combinations of the unit at the service feeder. The capacitor power rating is replaceable by other capacities of 15 20 kVar for different loading conditions. From a viewpoint of efficiency, the number of capacitors on a compensation unit should have enough electrical steps that can meet the demands of inductive loads.

Step 3. Calculate the fuel-saving when running an alternator without and with adding capacitors. This study computes the fuel-saving of running an alternator under various load power factor conditions based on the apparent output power of an alternator, namely simple approximation method [2]. The fuelsaving (FS) formula based on the apparent output power of an alternator is repeated as below:

$\mathrm{FS}_{\mathrm{i}}=\sum_{\mathrm{i}=1}^{\mathrm{n}}\left(\frac{\mathrm{M}_{\mathrm{t} 2, \mathrm{i}}-\mathrm{M}_{\mathrm{t} 1, \mathrm{i}}}{\mathrm{S}_{1, \mathrm{i}}} \times \mathrm{cf} \times \mathrm{S}_{2, \mathrm{i}}\right)$

where $S_{1, \mathrm{i}}$ and $S_{2, \mathrm{i}}$ represent the $\mathrm{i}^{\text {th }}$ average apparent power output of an alternator without and with adding capacitors (kVA), respectively. $\mathrm{M}_{\mathrm{t} 1, \mathrm{i}}$ and $\mathrm{M}_{\mathrm{t} 2, \mathrm{i}}$ are the readings of the fuel oil tank level at the beginning and at the end of the test without adding capacitors at the $i^{\text {th }}$ output power generation per hour (ton), respectively. $n$ is the amount of the $i^{\text {th }}$ output power generation divided per voyage, and of is the correction factor for fuel oil consumption in other ambient conditions to indicate the alternator efficiency when considering the degradation of an alternator's life limited parts. Thus, the fuel cost saving (FCS) with the installation of capacitors is yielded to be

$\mathrm{FCS}_{\mathrm{i}}=\sum_{\mathrm{i}=1}^{\mathrm{n}}\left(\mathrm{FS}_{\mathrm{i}} \times \mathrm{RT}_{\mathrm{i}} \times \mathrm{FP}\right)$ where $\mathrm{FCS}_{\mathrm{i}}$ is the FCS when running an alternator with capacitors at the $\mathrm{i}^{\text {th }}$ output power generation (USD), $R T_{i}$ is the average running time for the $i^{\text {th }}$ output power per voyage (h), and FP is the fuel price (USD/ton). Although the potential annual FCS of marine diesel engines is mainly dependent on the operating condition and duration of navigating a ship, its calculation in this study is based on three operation modes: maneuvering, hotelling and fishing operations during which freezers are turned on.

\section{Test results and discussions}

\subsection{Design consideration}

The compensation unit is placed downstream of the alternator in this study. Due to limited space and safety considerations in a ship, the cabinet is installed in a cool and well ventilated place. A single-line diagram of the designed unit consisting of a protection unit, a command and control unit, a display unit and a compensation unit up to $120 \mathrm{kVar}$ mounted in a common enclosure.

To determine the size of the capacitor bank, some considerations are illustrated below:

(i) Ship energy inspection: If the average power factor in a vessel is higher than 0.9 lagging, there is no need to correct power factor. However, if the power factor is less than 0.8 lagging, there is a need for correction, and the targeted power factor is specified as 0.9 lagging and above.

(ii) Power factor for alternator sets: To ensure the generating capacity that does not exceed the prime mover with a working capacity, the alternator's power factor is chosen to be 0.8 because alternator sets are generally rated in $\mathrm{kVA}$ at 0.8 power factor lagging. If the alternator rating is greater than the maximum power of the load, there is no need to install capacitors.

(iii) Capacitor selection. Compensative capacitors must be able to withstand the system voltage. The allowable over voltage is limited to within $10 \%$ of the rated voltage in 8 hours per day. Moreover, capacitors should have the ability to withstand a higher level of excessive voltage when considering the harmonic content of a system.

(iv) Circuit design. Since the relative humidity is usually very high within a ship, working 
temperature of the power factor correction equipment is a fundamental parameter for safe operation.

\subsection{Field test results}

Two vessels were tested to evaluate the fuel saving potential with the designed compensative unit for the desired power factor (PF) of 0.95 lagging. Fig. 2 shows the single-line diagram of the electrical distribution of the ship's power and Fig. 3 shows the inspection of their energy use in a voyage before power factor correction (PFC). As seen in Fig. 3, the total loads of a 500 -ton vessel is about $80 \sim 120 \mathrm{~kW}$ with a PF of 0.8 lagging when one of the two freezers that are installed on the ship is turned on; the total loads of the 700-ton vessel is about $150 \sim 350 \mathrm{~kW}$ with a PF of 0.8 lagging when three of the four freezers are turned on. Since the average PF of the two vessels is less than 0.8 lagging, the power factor improvement is required.

Since it is desired to correct the load to a power factor of 0.95 lagging, the total capacitances in 60 $\mathrm{kVar}$ and $120 \mathrm{kVar}$ are needed for the 700-ton and 500-ton vessels, respectively. Measured data are taken on the vessels operated in a voyage after installing PFC capacitors. As seen in Fig. 4, the total operated load of the system was $80 \sim 100 \mathrm{~kW}$ with a lagging PF of 0.8 . One hour and 15 minutes later, the strategy for compensating the reactive power by using an automatic power factor regulator (APFR) with four steps of $15 \mathrm{kVar}$ was adopted to appropriately follow the reactive power load in order to reach the target PF. For the same working loads, the

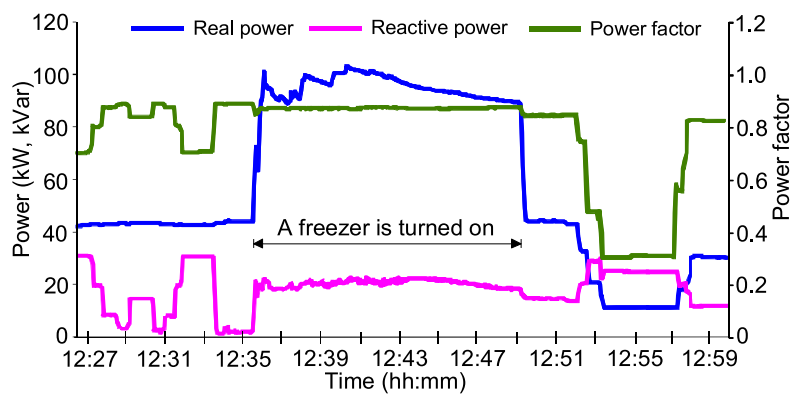

(a)

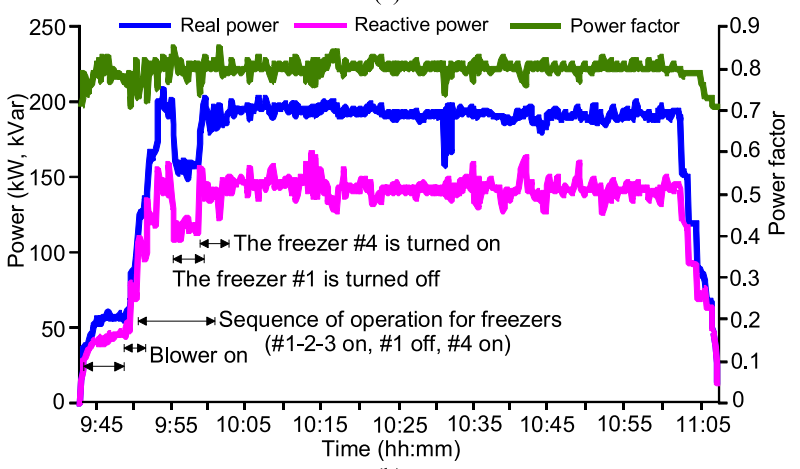

(b)

Fig. 3. Measured results of the studied vessels operated in a voyage without power factor improvement. (a) 500-ton vessel (b) 700-ton vessel.

apparent power was reduced from $80 \mathrm{kVA}$ to 68 kVA and the reactive power was reduced from 44 $\mathrm{kVar}$ to $18 \mathrm{kVar}$. Just after 13:15, capacitors were switched off by a controller and the PF dropped below 0.8. As seen in Fig. 5, the total operated load of the system was $200 \mathrm{~kW}$ with a lagging PF of 0.8 . One day later, the strategy for compensating the reactive power by using the designed APFR with 12 steps of $10 \mathrm{kVar}$ was adopted to appropriately follow

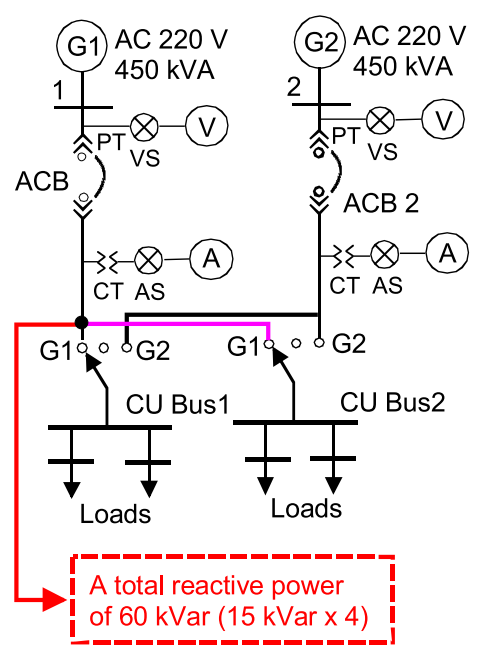

(a)

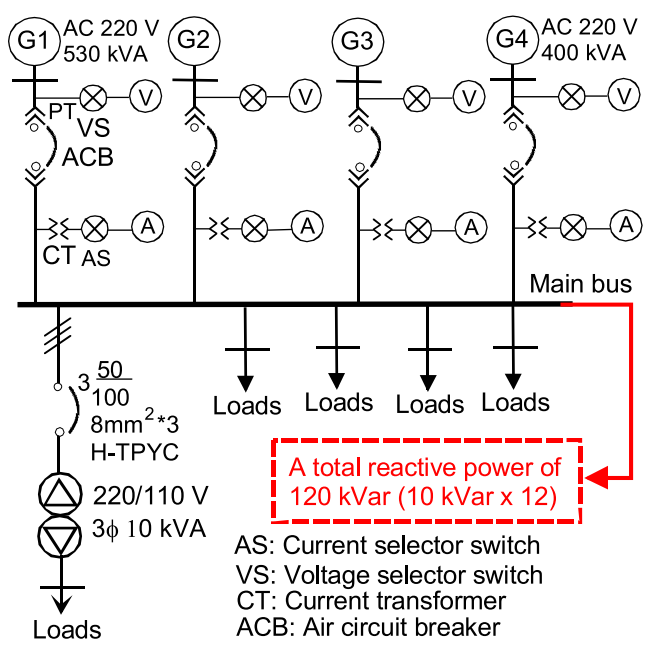

(b)

Fig. 2. Single-line diagram of a distribution network on the studied vessels connected with capacitor banks. (a) 500-ton vessel (b) 700-ton vessel. 

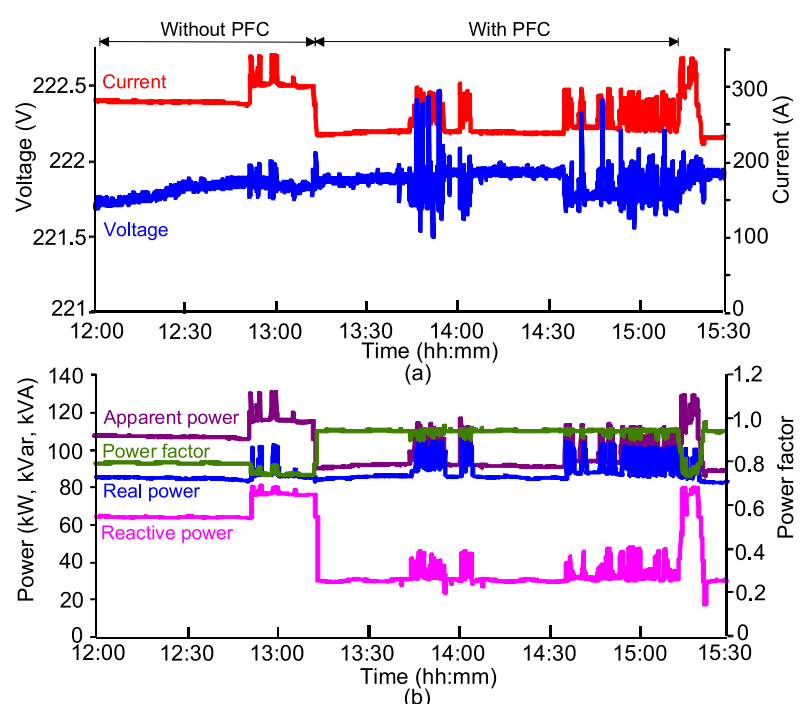

(b)

Fig. 4. Measured results of the studied 500-ton vessel operated in a voyage after installing power factor correction capacitors.

the reactive power load in order to reach the target PF. For the same working loads, the compensating unit will reduce above $40 \mathrm{kVar}$ of the apparent power demand on the system and the reactive power was reduced from $140 \mathrm{kVar}$ to $70 \mathrm{kVar}$.

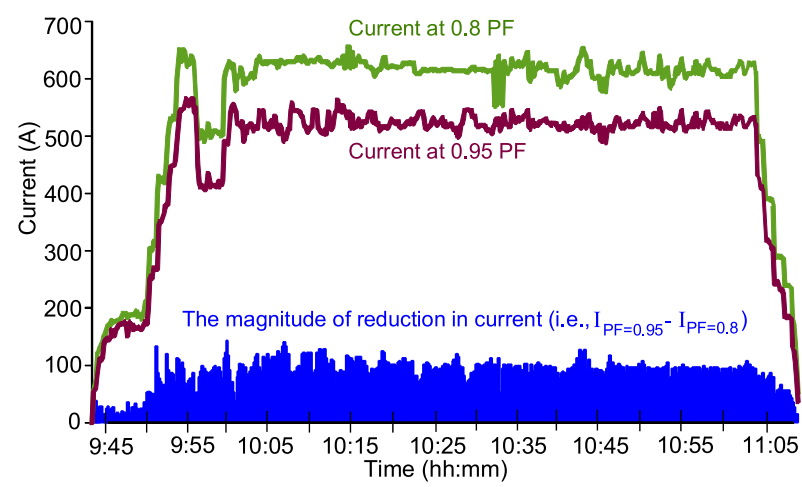

(a)

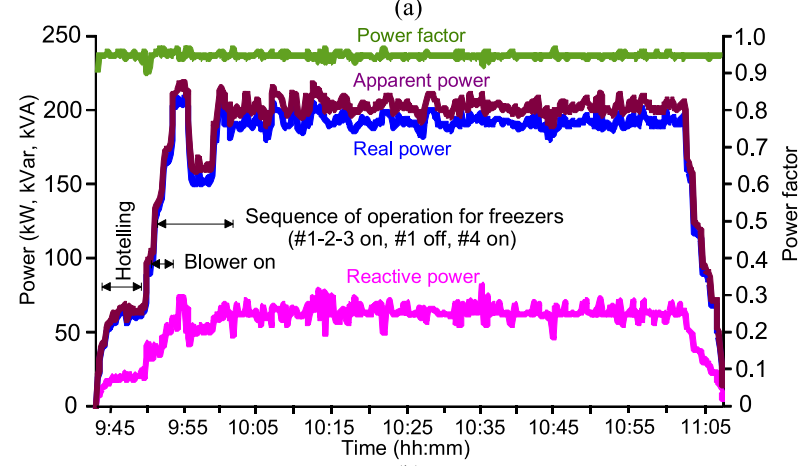

(b)

Fig. 5. Measured results of the studied 700-ton vessel operated in a voyage after installing power factor correction capacitors.

\subsection{Economic evaluation of power factor improvement}

\subsubsection{On the 500-ton vessel}

Before switching on the compensative unit, the average values of real power, reactive power, current, voltage and power factor measured at the main bus under maneuvering and hotelling operations with turning on one freezer for a full 24 hours were $88.49 \mathrm{~kW}, 54.25 \mathrm{kVar}, 290 \mathrm{~A}, 223 \mathrm{~V}$ and 0.79 lagging, respectively. After energizing the capacitor bank for the desired power factor of 0.95 lagging, these measurements under the same loading conditions were $87.69 \mathrm{~kW}, 28.82 \mathrm{kVar}, 243 \mathrm{~A}$ and $223 \mathrm{~V}$. With an improved power factor, it has saved nearly 40 liters per day. Table 2 summarizes the alternator parameter measurements during various loading conditions. As seen in Table 2, since the average alternator fuel consumption rate at half load tested by a laboratory was $235 \mathrm{~g} / \mathrm{kWh}$, this value is likely to increase in practice, resulting in a value of $270.25 \mathrm{~g} /$ $\mathrm{kWh}$.

To further illustrate getting a better fuel economy for corrected power factors, investigations were performed on board the ship departed on the 26day voyage in 2017. The average values of real power, current, voltage and power factor measured at the main bus that the ship was engaged in navigating with partial and full motor loads with turning on one or two freezers were in the range of $[100,120]$ $\mathrm{kW},[270,340] \mathrm{A},[222,224] \mathrm{V}$ and $[0.78,0.95]$ lagging, respectively. Fig. 6 shows the alternator fuel consumption and the current flowing through the cable during the voyage before and after power factor correction (PFC). With having a power factor of 0.95 lagging, it has saved nearly 1,864 liters for the 26day.

\subsubsection{On the 700-ton vessel}

Considering the time-varying characteristics of the load on the 700-ton vessel, the results of parameter estimation came from the actual measurements in a time window size of one hour during which three situations were examined: maneuvering and hoteling, turning on the fans in the freezer and engine compartments, and engaging in fishing operations while controlling the freezer temperature by turning on three freezers. Before switching on the compensative unit, the average values of real power, reactive power, apparent power, current, voltage and power factor measured at the main bus for a full 24 hours were $192.65 \mathrm{~kW}$, $142.88 \mathrm{kVar}, 239.34 \mathrm{kVA}, 618 \mathrm{~A}, 223 \mathrm{~V}$ and $0.8 \mathrm{lag}-$ ging, respectively. Moreover, the alternator's fuel consumption for one hour was 80.09 liters. After 
Table 2. Alternator parameters of the 500-ton vessel measured per hour.

\begin{tabular}{|c|c|c|c|c|c|c|c|c|c|}
\hline \multirow[t]{3}{*}{ ALT. output power $(\mathrm{kW})$} & \multirow[t]{3}{*}{ Fuel consumed by ALT. (g/kWh) } & \multirow{2}{*}{\multicolumn{2}{|c|}{$\begin{array}{l}\text { Avg. } \\
\text { lagging PF } \\
\text { PFC unit }\end{array}$}} & \multirow{2}{*}{\multicolumn{2}{|c|}{$\begin{array}{l}\text { Avg. output } \\
\text { current (A) } \\
\text { PFC unit }\end{array}$}} & \multirow{2}{*}{\multicolumn{2}{|c|}{$\begin{array}{l}\text { Avg. output } \\
\text { voltage (V) }\end{array}$}} & \multirow{2}{*}{\multicolumn{2}{|c|}{$\begin{array}{l}\begin{array}{l}\text { Avg. } \\
\text { efficiency } \\
(\%)\end{array} \\
\text { PFC unit }\end{array}$}} \\
\hline & & & & & & & & & \\
\hline & & on & off & on & off & on & off & on & off \\
\hline 38 & 239.3 & 0.93 & 0.79 & 105.6 & 124.8 & 223.3 & 222.5 & 85.9 & 84.4 \\
\hline 63 & 237.4 & 0.94 & 0.78 & 173.3 & 209.7 & 223.2 & 222.3 & 87.5 & 85.9 \\
\hline 104 & 232.7 & 0.95 & 0.79 & 283.1 & 341.7 & 223.3 & 222.4 & 88.6 & 87.0 \\
\hline 122 & 230.9 & 0.96 & 0.79 & 328.4 & 401.1 & 223.4 & 222.3 & 89.6 & 87.9 \\
\hline 154 & 227.9 & 0.96 & 0.80 & 414.9 & 499.5 & 223.2 & 222.5 & 91.3 & 89.5 \\
\hline
\end{tabular}

Table 3. Economic evaluation results of implementing the PFC system on the studied vessels.

\begin{tabular}{llllll}
\hline Items & & 500 -ton vessel & & \multicolumn{2}{c}{700 -ton vessel } \\
& & Without PFC & With PFC & Without PFC & With PFC \\
\hline Capital and maintenance costs (USD) & & 0 & 6,550 & 0 & 7,145 \\
Annual fuel consumption with (ton) & Measured & 234.47 & 221.33 & 312.80 & 303.77 \\
& SAA & 234.47 & 223.33 & 312.80 \\
Annual fuel cost saving (USD) & Measured & 6664.60 & & 4580.01 \\
Annual carbon emission cost saving (USD) & SAA & 5650.20 & 4651.02 \\
Annual carbon emission reduction (ton) & Measured & 59.24 & 40.71 \\
& SAA & 50.23 & 41.34 \\
ROI with (years) & Measured & 35.47 & 24.38 \\
& SAA & 30.07 & 24.75
\end{tabular}

Notes: Calculation is based on the diesel fuel price 507.2 USD\$ per ton of CPC in Feb. 2018 (the average price of international crude oil per barrel is 63.4 USD), the combustion of 1 liter of diesel fuel produces around $2.7 \mathrm{~kg}$ of $\mathrm{CO}_{2}$, annual interest rate at $2.14 \%$ and carbon tax of 1.67 USD per ton, and 1 NT\$ $=30$ USD.

energizing the capacitor bank for the desired power factor of 0.95 lagging, these measurements under the same loading conditions were $192.27 \mathrm{~kW}, 63.57$ kVar, $202.51 \mathrm{kVA}, 522 \mathrm{~A}$ and $223 \mathrm{~V}$. The alternator's fuel consumption for one hour was 76.23 liters. With having a power factor of 0.95 lagging, it has saved nearly 3.86 liters for one hour. As such, the value obtained through calculation with assuming the constant $c f$ of 1.15 in (2) is 2.16 liters.

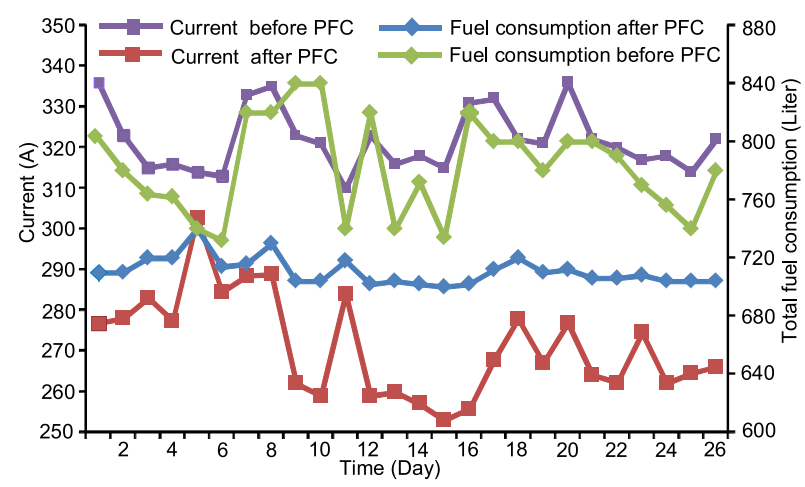

Fig. 6. Measured fuel consumption per day of the 500-ton vessel operated in a voyage before and after power factor correction.

\section{Payback analysis of the implemented APFR unit}

Table 3 summarizes the evaluation of implementing the APFR on the 500- and 700-ton vessels for one year. The alternator used in both vessels has the annual run time of 7,200 hours. As seen in Table 3 , about 9.03 tons of fuel oil for the 700-ton ship can be saved annually, resulting in a fuel oil cost saving of roughly 4,580 USD and a payback period of one year with the PFC system. Theoretically, about 9.03 tons of FOC can be saved using the simple approximation method (SAA), resulting in a cost saving of 4,651 USD. As a result, the corresponding payback period of 1.63 years can be yielded theoretically. In addition, about 13.14 tons of fuel oil for the 500-ton ship can be saved annually, resulting in a cost saving of roughly 6665 USD and a payback period of one year with the PFC system. Theoretically, about 11.14 tons of FOC can be saved using the SAA method, resulting in a cost saving of roughly 5,650 USD. As a result, the corresponding payback period of 1.19 years can be yielded theoretically.

Although the fuel cost saving associated with the use of PFC for marine electrical systems may vary, 
somehow depending on the size of the system, this study uses a break-even analysis (BEA) to quantify the benefits of PFC in terms of the reduced fuel and carbon emission costs. A quick measurement to assess the financial returns on PFC equipment is expressed as follows:

$\mathrm{X}_{\mathrm{T}}=\frac{\mathrm{F}+\mathrm{R}}{(\mathrm{FCS} \mathrm{i}+\mathrm{CT})-\mathrm{M}}$

where.

$\mathrm{X}_{\mathrm{T}}$ is the payback period (years).

$\mathrm{F}$ is the fixed capital investment of PFC equipment (USD).

$\mathrm{R}$ is the annual interest payment (USD).

$\mathrm{FCS}_{\mathrm{i}}$ is the fuel cost saving (USD).

$\mathrm{CT}$ is the carbon tax saving (USD), and.

$M$ is the cost of depreciation and maintenance on the PFC system (NT\$).

Note that the annual interest payment is ignored, since the fixed capital investment on PFC equipment does not involve a large amount of money. In addition, the carbon tax rate used in this study is USD 1.6 per ton.

To have a better understanding of the benefits in installing a PFC system on a ship, payback analyses were performed to identify the critical aspects of the investment. The parameters could include interest rates, fuel oil prices, maintenance costs and carbon emission tax. One of the vital effects, fuel oil prices in the payback period of a PFC system installed on the studied vessels was examined, based on the results of practical measures and SAA method, and the results are depicted in Fig. 7. By examining the fluctuations of international crude oil prices from 2013 to 2018, the impact of fuel oil price changes on the payback period was analyzed. In this paper, the average international crude oil price per barrel refers to the average crude oil prices in Brent Crude,

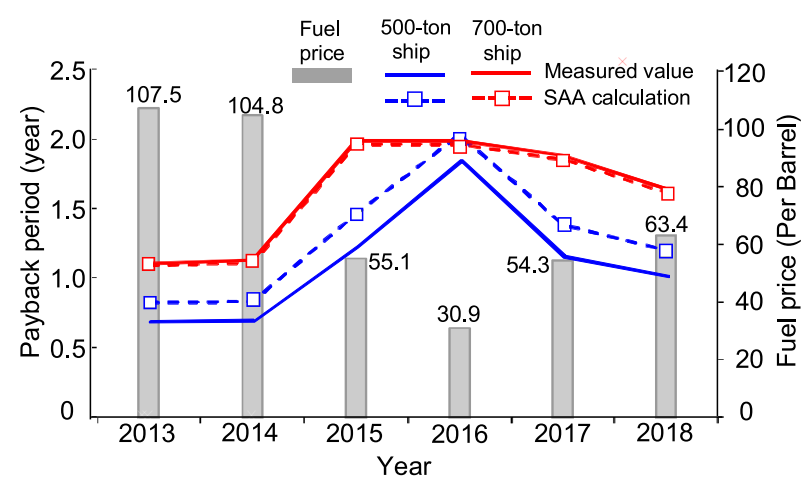

Fig. 7. Effects of fuel oil prices on the payback period of a PFC system installed on the studied vessel.
Dubai, and West Texas in February each year. As seen in Fig. 7, when the average price of international crude oil are 107.5, 104.8, 55.1, 30.9, 54.3 and 63.4 USD per barrel, the payback period for the 500ton ship based on the practical measurements will become $0.68,0.69,1.22,1.84,1.15$ and 1.01 years, respectively. Similarly, the trends can be found in the payback period for the 700-ton ship based on the practical measurements. Thus, energy saving from PFC improvements on a ship power system will result in more favorable economic benefits and paybacks when oil prices rise substantially.

\section{Conclusions}

This study presents two cases of implementing automatic power factor compensators (PFC) on marine power systems to solve low power factor problems while increasing fuel efficiency. To gain a better understanding of the benefits in installing a PFC system on a ship, fuel oil prices in the payback period of a PFC system installed on the studied vessels was examined based on the practical measurements as well as the simple approximation method related to the apparent output power of an alternator. The results show that rising oil prices will surely bring more favorable economic benefits for investment in energy-efficient ship retrofitted with installing a PFC unit.

\section{Acknowledgement}

This work was supported in part by the Ministry of Science and Technology, Taiwan, R.O.C. under Grant MOST 109-2221-E-006-080-MY3.

\section{References}

1 American Bureau of Shipping. Ship energy efficiency measures: status and guidance. 2017. Retrieved on Sep. 30, 2020, https://www.eagle.org/eagleExternalPortalWEB/

ShowProperty/BEA\%20Repository/References/Capability $\%$ 20Brochures/ShipEnergyEfficiency.

2 Lee $\mathrm{CH}, \mathrm{Hsu} \mathrm{SH}$. Assessment of energy savings on power factor improvement of marine electrical systems. J Marine Sci Techno 2015;20(3):475-86.

3 Mitra P, Venayagamoorthy GK. An adaptive control strategy for DSTATCOM applications in an electric ship power system. IEEE Trans. Power Electron 2010;25(1):95-104.

4 Prousalidis J, Hatzilau I, Michalopoulos I Pavlou, Muthumuni D. Studying ship electric energy systems with shaft generator. Philadelpha, PA, USA: IEEE Electric Ship Technologies Symposium; 2005.

5 Prousalidis J. The necessity of reactive power balance in ship electrical energy systems. J Marine Eng Technol 2011;10(1): 37-47.

6 Prousalidis J, Antonopoulos G, Mouzakis P, Sofras E. On resolving reactive power problems in ship electrical energy systems. J Marine Eng Technol 2015;14(3):124-36.

7 Su CL, Lin MC, Liao CH. A energy-saving evaluation method to justify automatic power factor compensators on marine 
vessels. USA: IEEE Industry Applications Annual Meeting, Las Vegas, NV; 2012.

$8 \mathrm{Su}$ CL, Lin MC, Liao CH. A method for evaluating energy efficiency to justify power factor correction in ship power systems. IEEE Transact Indust Appl 2013; 49(6):2773-82.
9 Taye A. Design and simulation of automatic power factor correction for industry application. Int J Eng Technol Manag Res 2018;5(2):10-21.

$10 \mathrm{Xu}$ XY, Mindykowski JM, Chen CL. Study on hybrid filtering solution for marine electric network. Polish Marit Res 2010; 17(2):72-8. 